\title{
HOW TO CHOOSE OPTIMAL LOCATIONS FOR INSTALLATION OF WIND TURBINES IN RURAL AREAS
}

\author{
*Vladimirs Vorohobovs, Martins Kleinhofs \\ Aeronautical Institute of Riga Technical University, Latvia \\ *Corresponding author's email: riga2006@inbox.lv
}

\begin{abstract}
To choose optimal place for wind turbine, you need to know two basic parameters:1. $V_{\text {avarage }}$ - the average wind throughout the year. The total amount of kilowatt hours of electricity you will get depends on this parameter. 2. $V_{\max }$ - the maximum possible dangerous gust of wind during a storm. The required strength depends on this parameter and hence also the cost of construction. In order to evaluate the chosen place, it is possible to combine these two parameters to only one physical parameter $V_{\text {bojat }}$ In this article it is called: "Average wind speed which is devaluated by hurricanes" or BOJAT speed.

These measurements must be done for a year or few years in advance. Two devices for such measurements are described in this article: the Anemometer and the Brazmometer. Both are purely mechanical, and that means - they are reliable and cannot loose dates because of some electrical shock. Both are made in Latvia. Also, recommendations how to make simple and cheap wooden mast for such measurements in rural area are given.

Key words: Return on investment, wind energy conversion, wind profile, anemometer, brazmometer, wooden tower, wooden mast for wind turbine.
\end{abstract}

\section{Introduction}

The locations for Wind turbine must be chosen correctly; otherwise, it brings only losses. How deep is the problem, can be seen in many publications, for example: Hübner \& Michelle, 2019; DW, 2014; Benson, 2021; Weissbach et al., 2014; Kruger, 2018; Joshua, 2018; European Wind Energy Association, 2009. That is why it is necessary to analyse the wind few years before the wind turbine construction.

The two parameters specified in the Abstract have a different effect on the choice of a wind turbine model. These two parameters can be reduced to only one physical parameter: an average speed, discounted by hurricanes. This parameter is introduced here for the first time; let us call it the Bojat Speed, formula 10.

For the final solution of the issue from an economic point of view, it is necessary to take into account other, not only physical, but also purely economic parameters: the price of electricity in the country, the demand for electricity in a given settlement, the average rate of return on investments in the World, the level of inflation, reliability of the equipment supplier, etc. Such an abundance of necessary information confuses decision-makers. One possible option striving to reduce the number of parameters is the usage of ball system (Baseer et al., 2017). But the idea which is proposed here has an advantage of objectivity, because it uses purely physical parameters.

\section{Materials and Methods}

The authors have created prototypes of two instruments for measuring these parameters: an anemometer and a brazmometer. The devices are purely mechanical and are cheap.

It makes no sense to buy one expensive electronic anemometer, which records the strength of the wind every second and transmits data via satellite communication to a computer, but does it only at one location. It is much better for the same money to use dozens of cheap mechanical devices at different locations. No one needs wind speed reports every second. In practice, only two integral figures are needed after a year of observation: the average wind speed and the maximum possible wind speed. But these two numbers must be collected in as many locations as possible.

A farmer who is considering the construction of wind turbine will be able to install several such measurement devices at different ends of his field, and after a year of observation he will be surprised to find that at some location the average wind blows stronger, and dangerous gusts of wind are weaker than elsewhere in the same field. That will give him the opportunity to get benefits from the correct placement of the wind turbine.

The first device is anemometer. It is used to measure average wind speed during a very long period.

The second device is used for measurement maximal possible dangerous wind gusts. We call it "Brazmometer". - "Brāzma" - gust of wind (Latvian).

The brazmometer records only one figure - the strongest wind which was during long observation $\mathrm{V}_{\max }$.

Usage of Logarithmic scale or Beaufort scale.

Problem: The Force of wind pressure is proportional to the square of Wind Speed.

So, if Wind changes ten times $5<$ Wind Speed $<$ $50 \mathrm{~ms}^{-1}$, then the Force (dynamic pressure) changes hundred times $25<$ Force $<2500$ units.

It is inconvenient to show such a huge range on one single dial. That is why the Logarithmic scale may be more suitable. Alternative and more traditional 

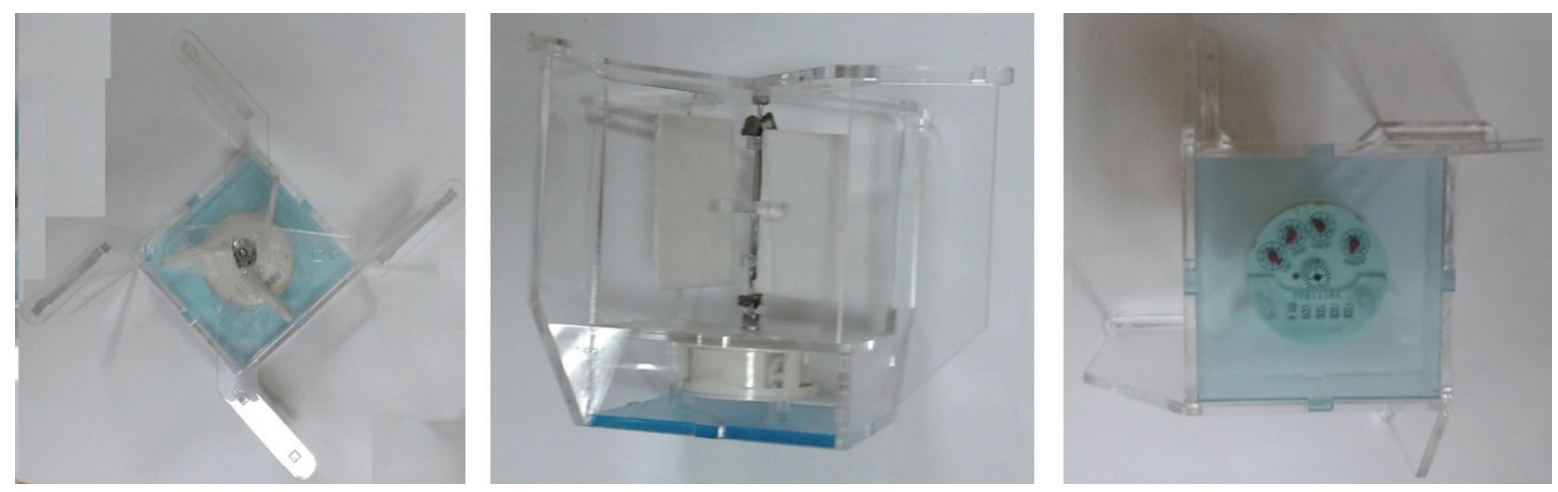

Figure 1. The Anemometer. Photos from different sides. Made in Latvia.

In the end of measurement, you will receive only one figure - the total distance. Dividing it on time you will get the average wind speed $-V_{\text {avarage }}$.
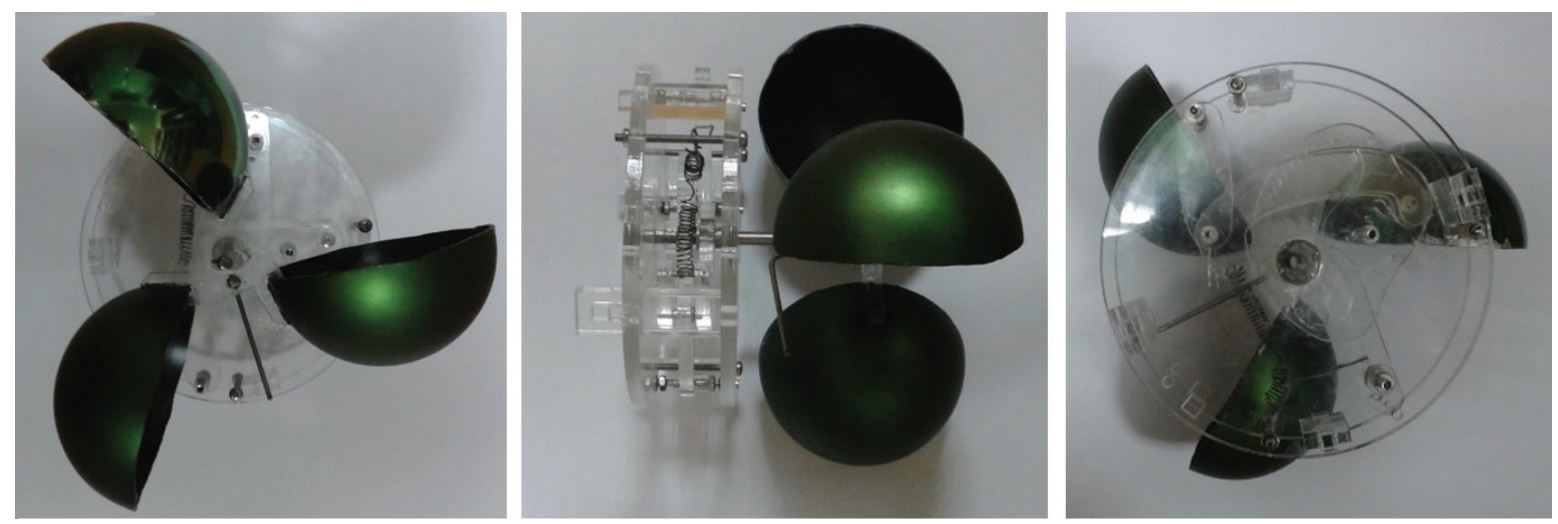

Figure 2. The Brazmometer. Photos from different sides. Made in Latvia.

approach is the usage of Beaufort scale. Defined by following Formula:

$$
V=0.836^{*} B^{3 / 2} \mathrm{~m} \mathrm{~s}^{-1}
$$

("Beaufort Scale". Encyclopædia Britannica.)

So, $B$ - the Beaufort is cubic root from the force caused by the wind pressure.

To make the angle of rotation of the arrow "Beautfort-dependent" on the force of the wind, a special mechanism was invented. This technical solution is in the process of being patented.

Practical methodological mast in rural area

Although in the future you plan to invest a large sum of money in the construction of a large wind turbine with a mast height of $40 \mathrm{~m}$, but for a preliminary estimation of the wind it is quite possible to use a mast with a height of $10 \mathrm{~m}$.

In rural areas of Latvia, it is easy to find three tree trunks, each $4-5 \mathrm{~m}$ long, which can be overlapped and tied together with a wire or strong rope to form a $10 \mathrm{~m}$ mast. At the bottom, the mast may have a diameter of about $5-8 \mathrm{~cm}$, and at the top, about $1 \mathrm{~cm}$. At the top, a 1-m-bar must be nailed horizontally to the ends of which an anemometer and a brazmometer are attached.

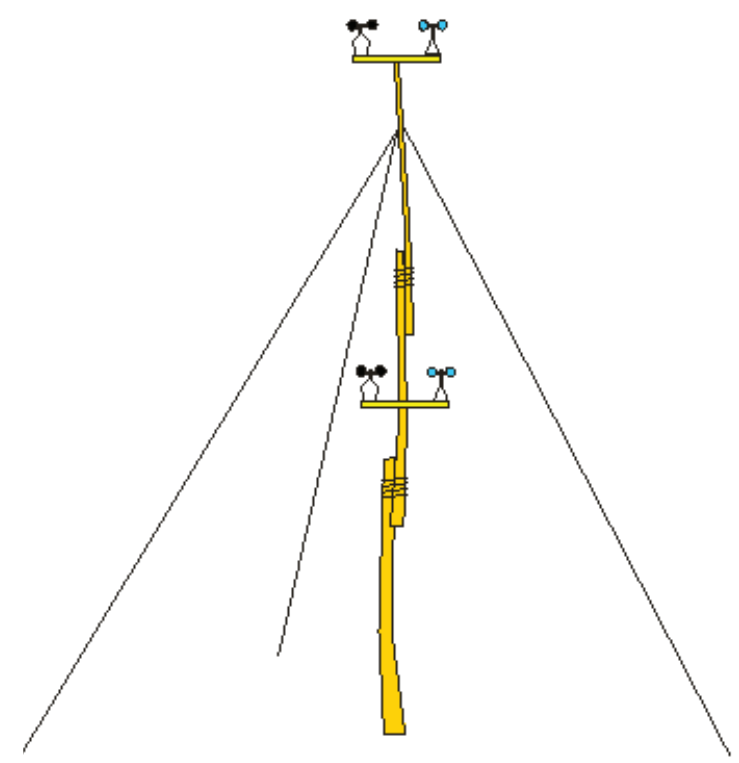

Figure 4. The cheap meteorological wooden mast in rural area with 3 stretched stabilising ropes. 
Such a mast does not need to be dug into the ground. It is much easier to reinforce it by making three ropes on different sides that are tied to three heavy anchors in the ground. Lot of advices how to build the mast are here (Geoff, 2013; Freere, 2004; Webb, 2007; Woofenden, 2009).

Any experienced farmer can make it on his own. However, calibrated devices must be purchased. This small investment will help you to avoid making big mistakes when planning a large and powerful wind turbine.

How to calculate wind at $40 \mathrm{~m}$ (for example) using information taken from $10 \mathrm{~m}$ mast?

It will cost hundreds of times more to build a $40 \mathrm{~m}$ mast than a $10 \mathrm{~m}$ mast. Estimation about dependence between height and cost are here (Vorohobovs, 2019). Therefore, it is advisable to start with a smaller mast for the preliminary study. Good example is here (Tore, 1999).

At a height of $5 \mathrm{~m}$, a second horizontal bar should be nailed, and two more devices installed on it. This helps to understand how the wind increases with height. This will allow you to roughly calculate the average and maximum speeds at bigger height, for example at $40 \mathrm{~m}$, measuring speeds only at $5 \mathrm{~m}$ and $10 \mathrm{~m}$. Just use a formula for the distribution of wind by height.

$$
\frac{V_{z}}{V_{10}}=\left(\frac{z}{10}\right)^{\mathrm{a}}
$$

Where $\mathrm{V}_{10}$ - is the speed at height $10 \mathrm{~m}, \mathrm{~V}_{\mathrm{z}}$ is wind speed at height $\mathrm{Zm}$, and $\mathbf{a}-$ is some coefficient which can be from 0.1 to 0.4 depending from local meteorological peculiarities. This formula can be found here: (Justus, 1976) and here (Emeis, 2001). Many other models are listed in (Archer, 2005).
This formula works both for average wind speed and for maximal wind speeds, but different coefficients a can occur in different locations.

So the a-need is to be calculated first. To do so, it is needed to measure the speeds $\mathrm{V}_{5}$ and $\mathrm{V}_{10}$ at two heights 5 and $10 \mathrm{~m}$, and calculate it by formula:

$$
\mathrm{a}=\frac{\log \left(V_{10} / V_{5}\right)}{\log \left(\frac{10}{5}\right)}=3.32 * \log \left(V_{10} / V_{5}\right)
$$

and then knowing $\mathbf{a}$ it is possible to calculate prognoses for $\mathrm{V}_{40}$ using formula (3).

Dependence between average speed and average power

The power produced by the wind generator is proportional to the cube of the wind speed. Therefore, the average wind speed is not exactly the parameter that is responsible for the power produced. However, it is known from practice (Lilienthal, 2021) that the speed distribution obeys approximately the Weibull distribution, which is the same in all countries and continents.

$$
f(V)=\frac{K}{A}\left(\frac{V}{A}\right)^{K-1} \exp \left(-\left(\frac{V}{A}\right)^{K}\right)
$$

This probability distribution in this formulae is already normalized. Here $\boldsymbol{A}$ is the Weibull scale parameter in $\mathrm{m} \mathrm{s}^{-1}$; a measure for the characteristic wind speed of the distribution. $\boldsymbol{A}$ is proportional to the mean wind speed $\boldsymbol{V}_{\text {avarage }}$. The coefficient of proportionality slightly depends from $\boldsymbol{K}$ but approximately $\mathrm{A}=1.13 * \boldsymbol{V}_{\text {avarage }}$ and $\boldsymbol{K}$ is the Weibull form parameter. It specifies the shape of a Weibull distribution.

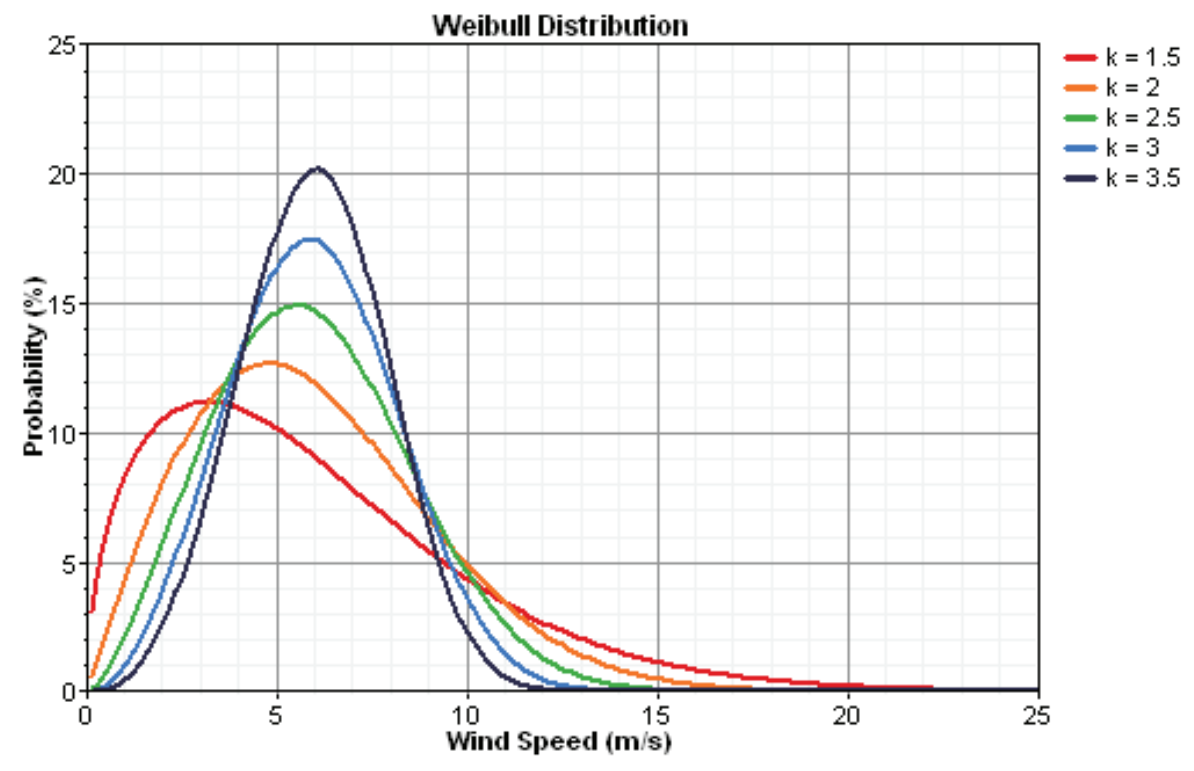

Figure 4. Wind speed distribution for different $\boldsymbol{K}$ (Lilienthal, 2021). 
The total reading of anemometer will be proportional to the value:

$$
\operatorname{Average}(V)=\int_{0}^{\infty} V * f(V) d V
$$

At the same time, the mean wind power density will be proportional to the value:

$$
\operatorname{Average}\left(V^{3}\right)=\int_{0}^{\infty} V^{3} * f(V) d V
$$

To estimate the relationships of these two kinds of averaging, some mathematical work is needed. Let us compare the result for three possible values of coefficient $K$ :

$$
\begin{aligned}
& \operatorname{Average}(V)=0.716 *\left(\text { Average }\left(V^{3}\right)\right)^{\frac{1}{3}} \\
& \text { at } K=1.5 \\
& \operatorname{Average}(V)=0.806 *\left(\operatorname{Average}\left(V^{3}\right)\right)^{\frac{1}{3}} \\
& \text { at } K=2.0 \\
& \operatorname{Average}(V)=0.859 *\left(\operatorname{Average}\left(V^{3}\right)\right)^{\frac{1}{3}} \\
& \text { at } K=2.5
\end{aligned}
$$

(Easiest way to calculate these coefficients is to use Wolfram Alfa computational intelligence).

According to Lilienthal, 2021, in majority of locations $1.8<\boldsymbol{K}<2.2$ and never goes beyond the interval $1.5<\boldsymbol{K}<2.5$.

This experimental observation makes it possible to compare the average wind speed and cubic root from the cubic average wind speed. Roughly all three above mentioned formulae can be written as:

$$
\begin{aligned}
& \operatorname{Average}(V)=0.8 *\left(\operatorname{Average}\left(V^{3}\right)\right)^{\frac{1}{3}} \\
& \pm 5 \% \text { possible mistake. }
\end{aligned}
$$

That means, that instead of the hard-measureable average cubic wind speed responsible for mean power, it is possible to use the mean wind speed easy measureable by a simple anemometer. And then multiply it by a coefficient $1.25=1 / 0.8$ and raise it to the third power.

However, it should be understood that such a simple pattern does not apply to dangerous gusts of wind. The fact is that dangerous gusts of wind occur only during hurricanes. And hurricanes come from far away. They are formed thousands kilometres away above the oceans, and the local topography does not affect on them as strong as it affects on the mean wind. Of course, some dependence between two kinds of averaging still exists, but it makes no sense to analyse it because during hurricanes the wind turbines do not function.

Therefore, hurricane statistics should be kept separately and not squeezed into the tail of the general Weibull distribution.

\section{Results and Discussion}

Economical aspect and the idea of mean wind speed which is devaluated by hurricanes (Name proposed: "Bojat wind speed")

A wind generator has its own cost, which is an investment. The cost price is proportional to the weight of materials spent on construction. And the weight of the materials used is proportional to the required strength. The dangerous breaking pressure that some gust of wind can exert is proportional to the square of the wind speed $V$. Information about hurricanes can be taken from different methodological sources, for example Brooks, 2003.

Therefore, it can be argued that the cost of building a generator is proportional to the square of the maximum possible speed of a gust of wind in a given location.

On the other hand, it can be considered that the income received is proportional to the power of the wind generator, which is proportional to the average cube of wind speed.

Therefore, the income from investments in wind energy will be proportional to one physical parameter:

$$
V_{\text {bojat }}=\frac{V_{\text {average }}^{3}}{V_{\max }^{2}}
$$

Where: $V_{\text {avarage }}-$ is the mean wind throughout the year, $V_{\max }$ - the maximum possible dangerous gust of wind during a storm. $V_{\text {bojat }}$ - is one integrated parameter which helps to evaluate suitability of the place for wind power.

$\mathrm{V}_{\text {bojat }}$ is nothing else but some effective speed measured in meters per second. The name is suggested: Average wind speed devalued by hurricanes or the Bojat Speed from Latvian language Bojats (Spoiled, Devaluated). It will always be significantly less than the real average wind speed.

For economic calculations and for making final decision to build or not to build a wind turbine, it should be multiplied by all kinds of economic coefficients such as the cost of electricity, profitability of a bank loan, demand for electricity and so on, like it is done here (Garrad, 2021). But this is not the purpose of this article which is limited only to physics.

Information on the average wind speed devalued by hurricanes (the Bojat speed) is a basic physical parameter for wind energy projects and should be measured before any consideration of future construction begins.

From two places, the one with the best $\boldsymbol{V}_{\text {bojat }}$ parameter should always be chosen.

Unfortunately, till now only maps for the mean wind are available in the Internet. This leads to erroneous conclusions, for example:

Looking at these maps, you might think that Latvia and Mexico have roughly the same opportunities for 

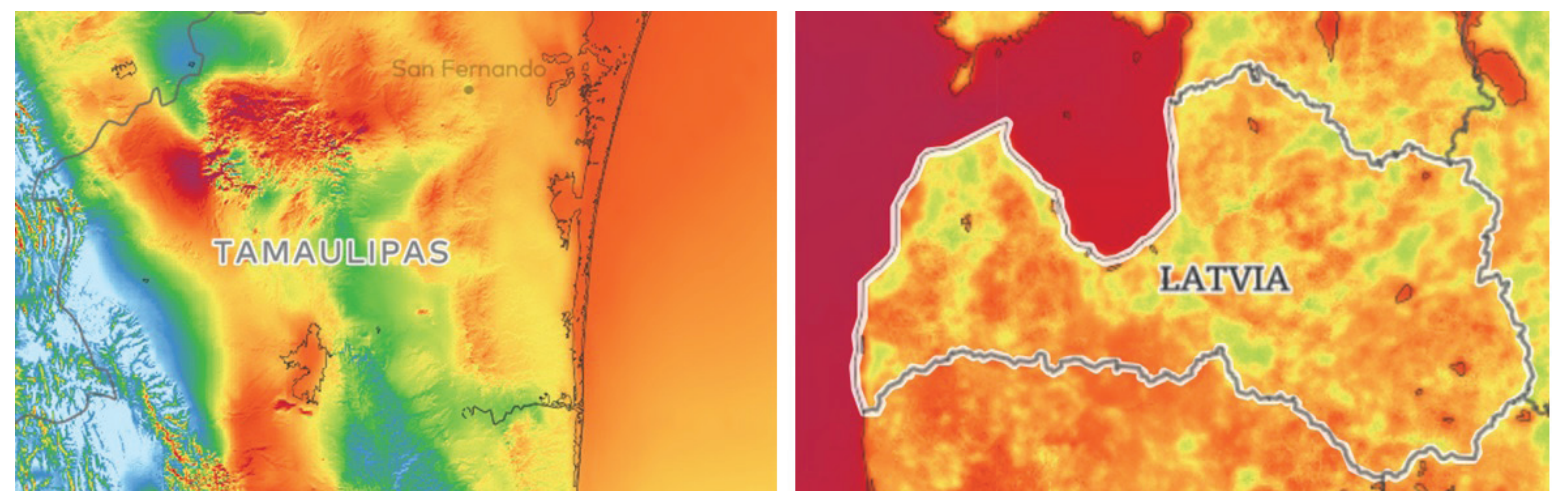

Figure 7. Average wind speed. Mexico Tamaulipas (left), Latvia (right).

Source:(Global wind atlas).

wind energy development, because both have areas which are marked with brown colour which symbolizes average wind speed $V_{\text {avarage }}=8 \mathrm{~ms}^{-1}$. But it is an incorrect conclusion. In Mexico, in 2015 was Hurricane Patricia, when the wind achieved its record peak intensity with maximum wind gust of $V_{\max }=96 \mathrm{~m} \mathrm{~s}^{-1}$ (Todd, 2016). On the other hand, for Latvia the maximum wind gust was in $1967, V_{\max }=48 \mathrm{~m} \mathrm{~s}^{-1}$. (Latvijas vide geoloǵijas un meteorologijas centrs).

Using formulae above, we can calculate: $V_{\text {bojat }}=$ $0.055 \mathrm{~m} \mathrm{~s}^{-1}$ for Mexico and $V_{\text {bojat }}=0.22 \mathrm{~m} \mathrm{~s}^{-1}$ for Latvia.

So Latvia has the areas which are 4 times more profitable for wind energy than Mexico does! Not because the mean wind is stronger, but just because there is no need to make the Latvian wind turbines as hurricane-proof as in Mexico, and that is why they can be made 4 times cheaper.

\section{Conclusions}

The article introduces a new integral physical parameter - the BOJAT SPEED that allows you to compare the suitability of different places for installing the wind turbines.
This single parameter is the combination of two other physical parameters - average wind speed and maximum wind speed during a hurricane ...

The article describes the prototypes of two devices for measuring the average wind speed and maximum wind speeds that were created in Latvia. Thus, using these devices and having received these two digits, it is eventually possible to calculate one single digit for each given specific location.

Now the procedure is clear. Every farmer can do it: just make such measurements in several places and calculate the BOJAT SPEED for each place, then the exact place where this parameter will be biggest, will be the best place for installation the wind turbine. The Bojat speed is more informative than Classes of Wind power density which are traditionally used, for example here (Global wind atlas, 2021).

\section{Acknowledgements}

Thanks to the Institute of Aeronautics, its management and other colleagues for providing the laboratory for experiments, for their help and support, and for paying fee for our participation in this conference.

\section{References}

Archer, C.L., \& Jacobson, M.Z. (2005). Evaluation of global wind power. Journal of Geophysical Research, Vol. 110, D12110.

Baseer, M.A., Rehmanb, S., Meyerc, J.P., \& Mahbub, A. (2017). Reseach Gate. Energy. GIS-based site suitability analysis for wind farm development in Saudi Arabia. Retrieved July 22, 2021, from https:// www.researchgate.net/publication/320328038_GISbased_site_suitability_analysis_for_wind_farm_ development_in_Saudi_Arabia.

Benson, D. (2021). How much do wind turbines cost? Windustry. Retrieved July 22, 2021, from http://www. windustry.org/how_much_do_wind_turbines_cost.

Brooks, H. (2003). Severe thunderstorms climatology. Retrieved July 22, 2021, from https://www.nssl.noaa. gov/projects/hazard/totalthreat.html.

Davenport, A.G. (1965). "Relationship of wind structure to wind loading”. Symposium Wind effect on structures, paper No.2, H.M.S.O.

DW. (2014). German court kicks off insolvency proceedings for wind park group Prokon. Retrieved July 22, 2021, from https://www.dw.com/en/german-court-kicks-off-insolvency-proceedings-for-wind-parkgroup-prokon/a-17605564. 
European Wind Energy Association. (2009, March) The Economics of Wind Energy. Retrieved July 22, 2021, from https://www.ewea.org/fileadmin/files/library/publications/reports/Economics_of_Wind_Energy.pdf.

Freere, P., \& Robotham, T. (2004). Alternative Technology Association, Melbourne. Wind power: plan your own wind power system. ISBN 0957889542.

Garrad, H. (2021). Wind Energy. The Facts. The Annual Variability of Wind Speed, Retrieved July 22, 2021, from https://www.wind-energy-the-facts.org/the-annual-variability-of-wind-speed.html.

Geoff, S., \& Geoff, M. (2013). Wind systems. Australian guide to environmentally sustainable homes. Retrieved July 22, 2021, from http://www.yourhome.gov.au/energy/wind-systems.

Global wind atlas (2021). Retrieved July 22, 2021, from https://globalwindatlas.info.

Joshua, S. (2018, August) Wind Energy Prices Continue To Fall Due To Technology Advancements \& Cost Reductions. Retrieved July 22, 2021, from https://cleantechnica.com/2018/08/27/wind-energy-pricescontinue-to-fall-due-to-technology-advancements-cost-reductions/.

Justus, C.G., \& Amir, M. (May 1976). Height variation of wind speed and wind distributions statistics. Geophysical research letters. Vol. 3, Issue 5 pp. 261-264

Hübner, A., \& Michelle, M. (2019). German wind turbine maker Senvion files for insolvency. / REUTER. Retrieved July 23, 2021, from https://uk.reuters.com/article/us-germany-senvion/german-wind-turbinemaker-senvion-files-for-insolvency-idUKKCN1RL271.

Latvijas Vides, ǵgeolog̣ijas un meteorologijas centrs (Latvian Environment, Geology and Meteorology Center). Retrieved July 16, 2021, from https://www.meteo.lv/lapas/visstiprakie-veji-latvija?\&id=1844. (in Latvian).

Lilienthal, P. (2021). HOMER / Hybrid Optimization of Multiple Energy Resources Retrieved July 23, 2021, from https://www.homerenergy.com/products/pro/docs/latest/weibull_k_value.html.

Emeis, S. (2001). Vertical variation of frequency distributions of wind speed in and above the surface layer observed by sodar, Meteorologische Zeitschrift. Retrieved July 23, 2021, from http://www.remtechinc. com/.

Todd, B., Kimberlain, E.S., Blake \& Cangialosi, J.P. (2016). Hurricane Patricia. National Hurricane Center. Retrieved July 19, 2021, from https://www.nhc.noaa.gov/data/tcr/EP202015_Patricia.pdf.

Heggem, T. (1999). Thesis submitted in partial fulfilment for the degree Doctor Scientiarum, Norwegian University of Science and Technology, Trondheim Retrieved July 19, 2021, from https:/www.osti.gov/ etdeweb/servlets/purl/328146.

Vorohobovs, V., \& Zakharoff, A. (2019). The Dependence of the Optimal Size of a Wind Turbine Tower on Wind Profile in Height, Transport and Aerospace Engineering, Vol. 7, pp. 58-65. Retrieved July 19, 2021, from https://www.researchgate.net/publication/338026921_The_Dependence_of_the_Optimal_Size_ of a Wind_Turbine_Tower_on_Wind_Profile in_Height.

Webb, A. (2007). Alternative Technology Association Melbourne: The viability of domestic wind turbines for urban Melbourne, Retrieved July 23, 2021, from https://renew.org.au/wp-content/uploads/2018/11/ata report_domestic_wind.pdf.

Weissbach, D., Ruprechta, G., Hukea, A., Czerskia, K., Gottlieba, S., \& Husseina, A. (2014). Energy intensities, EROIs and energy payback times of electricity generating power plants. Retrieved July 23, 2021, from https://festkoerper-kernphysik.de/Weissbach_EROI_preprint.pdf. 